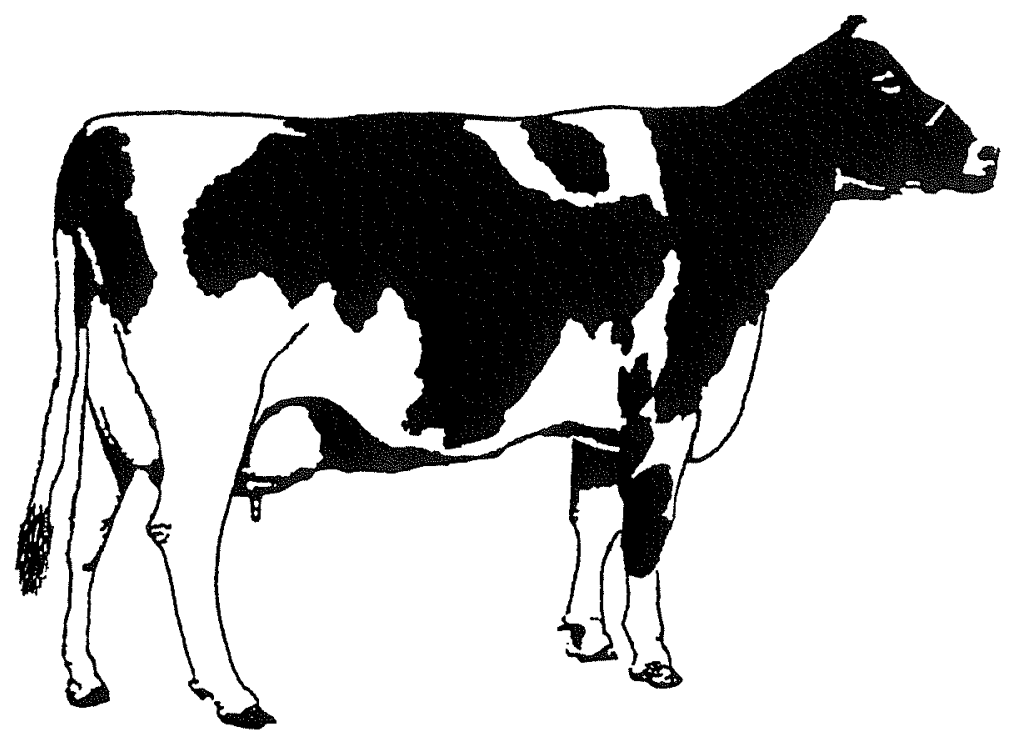

\title{
MAKING IT BETTER
}

\section{TIPS FOR IMPROVING ORAL REASON SCORES}

\section{FOR SENIOR MEMBERS}

Debra Summerall, James Umphrey and Russ Giesy University of Florida Cooperative Extension Service 


\section{MAKING IT BETTER \\ TIPS FOR IMPROVING ORAL REASON SCORES}

\section{INTRODUCTION}

By now you should know the basics of judging dairy cattle and giving reasons. However, high-scoring sets of reasons don't happen overnight; it is important to practice giving reasons often. Unfortunately, if you don't know how to fix a problem you are having with your reasons, practice may do more harm than good.

This booklet is designed to be a supplement to the oral reasons booklet. Where Booklet II told you how to prepare and present a set of oral reasons, this booklet will show you how to fix areas you may still be consistently low in. It will review each area of the oral reason scorecard and give ideas for improvement.

The activities described in this booklet are actually suggestions given by National Dairy Judging Team members who have experienced the same problems you are having and overcame them to go on and place high at national competitions. Contributors include Debra Summerall, Christy Betts, Alicia Churchwell and Matt Walter.

The basis for the techniques described came from James Umphrey, Russ Giesy and Debbie Clements.

If you use this booklet diligently in conjunction with Booklet II, success will follow. 


\section{PREPARATION}

Again, preparation deals with the areas of Format, Comparative Tense, Terminology, Accuracy, and Logic.

\section{FORMAT}

Format is an essential part of preparing your oral reasons. It is associated with how you take notes and the length of your reasons. For every 5 seconds over or under the 2:00 to 2:10 minute time limit, one point is subtracted from your score.

If you are consistently receiving a score lower than 5 in this area you should first look at the content of your notes. If you don't have enough notes you may consistently run short on time.

Activity: Look at a set of notes from a class you did not receive a 5 in format, possibly because you didn't have enough points to talk about. Ask yourself these simple questions to evaluate the quantity of your notes.

- Did you write a small description of the class to organize into an introduction of one to two sentences?

- Do you have 3 pro points to discuss for each pair and 1 grant?

- Have you made note of why you placed the last place animal on the bottom to organize into a two-sentence summary?

If you answered "no" to any of these questions, you know what to work on to make your notes more complete. It is very important that each set of notes you take have these three components.

Let's break these three questions down. You may wonder how to accomplish each of these three goals and why they are important. First off, making sure you have each of these elements plays a part in reaching the time limit goal. Secondly, these three components add to the flow of your reasons.

Introduction: Breaking the class down into either a top, middle or bottom pair, or a first, second and last pair will not only add time to your set of reasons, but also will enable them to flow better. By introducing your class, you give the judge an overview of what is to come and set the class up in your own mind to help you remember your major points.

3 Pro $/ 1$ Con: Making sure you have three major pro points to discuss for each pair is essential for a complete set of reasons. Three points proves that the animal on top is 
worthy of placing over the next place animal and so on. Three points also ensures you have enough to talk about to reach your minimum time goal.

When using your con statement, it is best to have a divider to let the judge know you are about to "grant" something back. The correct terminology for this is to say "I grant..." or "however, I grant..." or even "however, I concede..." for the more advanced members. On the last page of this booklet is a list of some more ways you can begin a grant.

Another great way to spice up a set of reasons and earn points for format is to label pairs by incorporating the transition phrases "close pair", "easy pair", "easily places over", and "in making this a close placing, I grant..." into your set of reasons.

Summary: A summary statement of why you placed the last animal on bottom is important to include in the transition from the last pair to the end of your reasons. It also reiterates to the judge why the animal was not worthy of placing any higher and adds valuable seconds to the end of your reasons.

Activity: Read the sample set of reasons below. Notice the use of an introduction, 3 pro/ 1 con and a summary. Circle the transition phrases suggested above and note how they were used. Next, look at a class from a magazine, place it and write a complete set of notes for the class. Re-ask the above questions to see if your new set of notes is complete. Incorporate some of the suggestions in your set of reasons and tape them.

In placing this class of Guernsey 3-year-old cows 4-1-2-3, I started the class off with an easy top in the well-uddered 4, followed by a close pair of tall, powerful animals in 1 and 2 , and ended the class with the weak-uddered and over-conditioned 3.

In my top pair, I place 4 over 1 for her tremendous advantage in mammary. She is higher, wider, fuller in her rear udder attachment, longer and snugger in her fore udder attachment, and more level upon the udder floor. In addition, she is the taller, more upstanding individual who is walking on a more desirable set of feet and legs when viewed from the side. She has less set to the hock, is shorter, stronger in her pasterns, deeper in her heel and steeper in her foot angle. To tip the balance even further, she exhibits more angularity and refinement throughout; being longer, leaner in the neck, sharper, more prominent over the withers, hooks and pins, and is flatter in the thigh. However, I grant that 1 exhibited more strength and power throughout.

In my middle pair, I place 1 over 2 in a rather close placing for she was longer, smoother in her fore udder attachment and more level upon the udder floor. One was also more level from hips to pins, straighter over the topline and smoother blending in the shoulder. Further, she was more open in her ribbing. However, in making this a close placement, 1 grant 2 was higher, wider in her rear udder attachment, taller at the point of withers and freer from excess flesh throughout.

It is this decided advantage in angularity and femininity that easily carries 2 over 3 in my bottom pair. Number 2 is longer in her neck, cleaner in the throat, sharper over her withers, more prominent about her hips and pin, flatter, more concave in her thigh and 
extremely more open in her ribbing. To compliment this, she exhibits a more youthful udder that is held higher above the hock and closer to the body wall. She is higher, wider, fuller in her rear udder attachment, longer, smoother, tighter in her fore udder attachment, more clearly defined in her medial suspensory ligament and more level upon the udder floor. I grant that 3 was wider on her chest floor.

Three places at the bottom of this class because she lacks the overall strength of mammary and refinement throughout to merit a higher placing today. These are my reasons for placing this class of Guernsey 3-year-old cows 4-1-2-3.

If you answered "yes" to the questions on the first page, your problem may lie in how fast or slow you talk while giving reasons. People who talk at a fast pace can actually subtract valuable seconds from a set of reasons and lose points from their score. Listening to someone talk very fast is not as enjoyable as listening to someone talk at a moderate speed. If you are a fast talker, you may not only be losing points in format, but in other areas as well.

However, you may be having the opposite problem of talking too slow. This may be adding seconds to your reasons, causing your time to be over the allotted amount. Dragging out a set of reasons gives the judge a chance to become disinterested in what you are saying. The judge's mind may begin to wander if you speak too slowly, inevitably causing him to subtract points from persuasiveness, as well as format.

Activity. Tape-record a set of reasons that you are having problems with. (This technique will be used more in other sections.) Play the recording back and time yourself with a stopwatch. Decide if your pace is too fast, moderate, or too slow. If you are having trouble determining your pace, ask a friend or relative to listen to the tape and decide for you.

- If your pace is too fast:

- try taking a deep breath before you give your next set of reasons. This will slow you down a bit and relax you.

- in casual conversation, consciously slow your talking pace down, it may sound funny at first, but it will become more natural the more you practice.

- If your pace is too slow:

- you may be talking slower due to nervousness. If this is the case, practice talking faster, eliminating unnecessary pauses and phrases. Record yourself over and over until your pace is fast enough to complete your reasons in 2 minutes. 


\section{COMPARATIVE}

To give effective oral reasons you must use comparative terms instead of descriptive. Simply describing every animal in the class is not going to tell the judge why you placed one cow over another. To successfully get your points across, you must compare each animal.

On the reasons scorecard, this is one area that is the easiest to receive a full 5 points in, unless you are not fully sure what terms are comparative and what terms are descriptive. If you are consistently losing points in this area, try the activities listed below.

Activity: Turn the descriptive sentences below into comparative sentences.

1. She is strong.

2. She has a lot of length from her hips to her pins and she is wide across her rump.

3. She is correct in her rump.

4. She has a high and wide rear udder attachment.

5. She is open in her ribbing.

After completing this activity, compose a set of written reasons using comparative terms. Review the list below to make sure you have used as many of the terms listed as possible.

\section{Comparative Term Examples}

$\begin{array}{lll}\text { higher } & \text { wider } & \text { fuller } \\ \text { longer } & \text { taller } & \text { cleaner } \\ \text { more correct } & \text { deeper } & \text { sharper } \\ \text { tighter } & \text { more open } & \text { more angular } \\ \text { more youthful } & \text { steeper } & \text { stronger }\end{array}$




\section{TERMINOLOGY}

Correct terminology is the basis of a convincing set of reasons. You should have a good grip on what terms are considered correct. It is important to understand that the use of impressive terms, such as medial suspensory ligament, will increase your reasons score. In turn, however, the use of poor terminology, such as "better" and "bag", will ultimately decrease your score.

Activity. If you are still unsure about the names of certain parts, spend some time looking over the scorecard. At the bottom of the scorecard is a picture of a dairy cow with the parts labeled. Learn the parts to complete the puzzle below.

1. $----$

2

2.

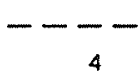

3.

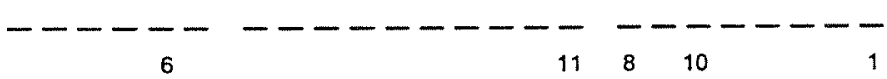

4.<smiles>C=CC</smiles>

5.

$$
5
$$

6.<smiles>C1CCC1</smiles>

3

7.

8.

$$
7
$$

CLUES:

1. "BAG"

2. AREA FROM HIPS TO PINS

3. "THE SEAM"

4. MEASURED AT THE HAIR LINE

5. MORE OPEN IN HER

6. DEPTH OF — _ PAIRED WITH GIRTH

7. BACK PART OF MAMMARY SYSTEM

8. FRONT PART OF MAMMARY SYSTEM

PUZZLE ANSWER 


\section{ACCURACY}

Seeing the class accurately is important to the content of your reasons. However, it is very easy to lose points in this category. The key to success in this area is incorporating a review process into your 20-minute time limit in the ring. The following is a breakdown of how the 20 minutes should be spent to insure accuracy in your notes and reasons.

\section{Placing the Class:}

Taking Notes:

Review notes for Accuracy/Memorize the Cows:

3-5 $\min$

$3-5 \mathrm{~min}$.

Use remaining time to review notes 2-3 times. Memonize cows and major points to be discussed.

Another way to improve in the accuracy of your oral reasons is to make sure you are clearly evaluating cattle with your priorities well in line with the scorecard.

In practice, if you are unable to place a class or have trouble with a pair, ask for help. Your coach would rather you ask for help than continue losing points due to inaccurate reasons. Low reasons scores also stem from presenting inaccurate points in your oral presentation. For example, if you state that you gave 1 the advantage in mammary over 2 , but the judge feels that 2 has the superior udder, points will be deducted from your score in this area.

Remember: The help you get will stick with you the next time you have a problem evaluating a class. Soon you will be scoring 5 for accuracy.

\section{LOGIC}

Logic deals with raising points in a discussion in an order which develops the strongest and most logical argument. If a judge feels you are practically reading "his own notes" while giving your set of reasons, he will be convinced you have a logical set of reasons and are very accurate with the points you have raised. This category goes hand in hand with the accuracy category. Most likely if you are lacking in one, you are lacking in the other as well.

Activity: If you are losing points in this area, find a picture of a class of dairy cows from Hoard's Dairyman. Begin evaluating the class. Once you have the class placed and are ready to begin writing your reasons, ask yourself the following questions:

What is the most important difference that places 1st over 2nd?

What is her next most important asset that places her first?

Keep asking these questions while forming your notes until you have a complete set. Practice your set and give them to your coach. Find out how logical you were by zomparing your coach's notes with yours. If they look practically the same, you did a great ob. If not, discuss the class with your coach. 


\section{ORAL PRESENTATION}

The presentation of your reasons ultimately will be what sets you apart from the other contestants in a major dairy judging contest. Most everyone will have placed the class right, or nearly right, and in turn, will practically have the same reasons for doing so. Therefore, it is important to present your reasons in an effective way. On the reasons scorecard there are five major categories: poise, body language, smoothness, voice manipulation and persuasiveness.

\section{POISE}

Poise is an area that you might not quite understand. It deals with your "carriage" as you enter the reasons room and the "presence" you create.

- Show confidence by smiling when entering the room.

- Make eye contact enthusiastically, like you are glad to be there.

- Show initiative by giving your contestant number before being asked.

- Own the room and the judge's time.

- Thank the judge for listening attentively.

Activity: Practice your poise in front of a mirror. Make sure you cover each of the tips listed above. Once you are confident that you are showing correct poise, ask an observer to critique you. Have them answer the following questions on a piece of paper.

1. Was the contestant smiling as he/she entered the room?

2. Did he/she make eye contact immediately?

3. Did the contestant take the initiative by giving his/her contestant number before being asked?

4. What kind of environment did the contestant create upon entering the room? Did you feel as if they were in control and excited to be there?

5. Before exiting, did the contestant thank you for listening attentively?

6. Please write a small critique of the contestant's performance in the area of poise. 


\section{BODY LANGUAGE}

It is important to appear assertive when entering an oral reasons room. Appearing either aggressive or passive will cause you to lose points in this area. Many people, however, may not know how to assume an assertive stance. Three main components of assertiveness are: standing a moderate distance from the person you are speaking to, erect body carriage, and looking comfortable while in the room. Looking comfortable deals with not fidgeting, keeping both feet a moderate distance apart, not moving them too much, and not swaying while you are giving reasons.

Activity: Here are some pointers to help you get used to assuming assertive body language:

- Practice giving a set of reasons in front of a mirror. Make sure you look yourself in the eye, have erect body carriage and are standing a moderate distance from the mirror. This may seem funny at first, but eventually you will be able to notice a difference in your body language.

- If you don't know what to do with your hands, hold them behind your back.

Once you become comfortable standing up straight, relaxing and assuming an assertive attitude, you will gain confidence in yourself and in turn carry your body better.

\section{SMOOTHNESS}

Smoothness is one of the greater challenges. To give a smooth set of reasons takes a lot of practice. The more reasons you give, the more natural it becomes and the smoother you sound.

Activity: The first step to improving in this area is to audio or videotape yourself giving a set of reasons. When listening to the tape, note areas where you seem to be having trouble. Try to understand why you where choppy in that area.

Were you using a phrase you were not comfortable with?

- Did you switch a pair of numbers and the mistake disrupted you?

Were you unsure of what terms and phrases to use? 
After answering these questions you will know what to improve on. If your trouble seems to lie in the area of phrases, try the next activity to improve.

Activity: Play "The Sentence Game". Have a friend or relative help you play. Give the person who is helping you a copy of the scorecard, or if you are going to play on your own, find yourself a copy of the scorecard. Starting at the Frame category, go through each component and come up with a phrase describing an animal with the advantage in that component.

Example: Rump - She is more level from hips to pin and wider across her rump. Stature - She is taller at the point of withers.

Practice each phrase until you are smooth and comfortable using it. Then, put all the phrases for each of the five categories together to form a sentence or two for each category.

Example: Frame - She has the advantage in frame; being more level from hips to pins and wider across her rump. She is taller at the point of withers, smoother blending in the front end, and straighter across the topline.

Practice each category phrase until you are smooth. Once you are confident about your smoothness, re-tape your set of reasons using the phrases you just practiced.

\section{VOICE MANIPULATION}

Voice manipulation is a major key in delivering an exciting, interesting and easy-to-listen-to set of reasons. The most convincing speakers use a normal, conversational voice, but work hard to keep the listener attentive by varying their pitch, tone, and loudness. However, one should not shout or talk too loud.

If you find yourself losing points in this area, a combination of the two activities listed below is the best way to improve.

Activity: Tape-record a set of reasons. Don't listen to them just yet. Then, practice fluctuating your pitch. Emphasize important words to add power and impact to a set of reasons. Look at the example below. Words in italics should be elongated and louder to add emphasis, words in bold should be emphasized by increasing pitch and loudness. Words in smaller letters require you to lower your pitch and loudness for emphasis.

She is extremely higher and wider in her rear udder attachment. 
Now tape a set of reasons again, making sure to emphasize important words. Listen to both sets and see if you can tell the difference.

Activity: Incorporating what you tried in the first activity, also try to add emphasis by pausing after important words instead of fluctuating your pitch.

Example: She is extremely higher (pause) and wider (pause) in her rear udder.

\section{PERSUASIVENESS}

Persuasiveness deals with how convincing you are. Most likely, if you are losing points in this area, you are also having problems in the other four presentation areas. If you take steps to correct your other deficiencies, you will automatically be correcting this one.

Remember: To make sure you are receiving the highest score (5) in persuasiveness, do not mix your numbers up when giving a set of reasons.

\section{CONCLUSION}

Winning sets of oral reasons do not happen overnight. If you are having troubles, don't become discouraged. Remember: Practice makes perfect. With a little time putting the activities in this booklet to work for you, you will be giving improved sets of oral reasons in no time.

Good Luck! 


\section{ADDITIONAL TERMS AND PHRASES TO DRESS UP REASON S}

- most complete animal

winning combination

- logical top

- tremendous advantage

- distinct advantage

further

to complement this further

- in addition

- I give her further advantage in

- greatly superior

- I do concede

however, I did not fail to recognize

- it is this advantage in __ that places 1 over 2 in my middle pair

- moving on to my pair

- I found a close pair

- I easily placed 
1. This document is 4HDAJ04 of the Florida 4-H Youth Development Program, Florida Cooperative Extension Service, Institute of Food and Agricultural Sciences, University of Florida. Published in May, 1997; reviewed June 2002.

2. Giesy, Russ and Umphrey, James. Edited by Debra Summerall. Animal Science Department, IFAS, University of Florida.

COOPERATIVE EXTENSION SERVICE, UNIVERSITY OF FLORIDA, INSTITUTE OF FOOD AND AGRICULTURAL SCIENCES, Christine Taylor Waddill, Director, in cooperation with the United States Department of Agriculture, publishes this information to further the purpose of the May 8 and June 30, 1914 Acts of Congress; and is authorized to provide research, educational information and other services only to individuals and institutions that function without regard to race, color, age, sex, handicap or national origin. The information in this publication is available in alternate formats. Single copies of extension publications (excluding 4-H and youth publications) are available free to Florida residents from county extension offices. Information on copies for out-of-state purchase is available from Publications Distribution Center, University of Florida, PO Box 110011, Gainesville, FL 32611-0011. 